\title{
A NEW CHARACTERIZATION OF DIFFERENCES OF GENERALIZED WEIGHTED COMPOSITION OPERATORS FROM THE BLOCH SPACE INTO WEIGHTED-TYPE SPACES
}

\author{
QINGHUA HU AND XIANGLING ZHU
}

\begin{abstract}
In this paper, we give a new characterization for the boundedness and compactness of differences of generalized weighted composition operators from the Bloch space into weightedtype spaces. Moreover, we give some estimates for the essential norm of these operators.
\end{abstract}

Mathematics subject classification (2010): 30D45, 47B38.

Keywords and phrases: Bloch space, difference, generalized weighted composition operators, essential norm.

\section{REFERENCES}

[1] E. BerKSON, Composition operators isolated in the uniform operator topology, Proc. Amer. Math. Soc. 81 (1981), 230-232.

[2] C. Cowen AND B. Maccluer, Composition Operators on Spaces of Analytic Functions, CRC Press, Boca Raton, FL, 1995.

[3] R. Hibschweiler And N. Portnoy, Composition followed by differentiation between Bergman and Hardy spaces, Rocky Mountain J. Math. 35 (2005), 843-855.

[4] T. Hosokawa And S. OHno, Differences of composition operators on the Bloch spaces, J. Operator Theory 57 (2007), 229-242.

[5] H. LI AND X. FU, A new characterization of generalized weighted composition operators from the Bloch space into the Zygmund space, J. Funct. Spaces Appl. Volume 2013, Article ID 925901, 12 pages.

[6] S. Li And S. STEvić, Composition followed by differentiation between Bloch type spaces, J. Comput. Anal. Appl. 9 (2007), 195-205.

[7] S. Li AND S. STEVIĆ, Composition followed by differentiation from mixed-norm spaces to $\alpha$-Bloch spaces, Sb. Math. 199 (12) (2008), 1847-1857.

[8] S. Li And S. Stević, Composition followed by differentiation between $H^{\infty}$ and $\alpha$-Bloch spaces, Houston J. Math. 35 (2009), 327-340.

[9] S. Li AND S. STEVIĆ, Products of composition and differentiation operators from Zygmund spaces to Bloch spaces and Bers spaces, Appl. Math. Comput. 217 (2010), 3144-3154.

[10] S. Li AND S. STEVIĆ, Generalized weighted composition operators from $\alpha$-Bloch spaces into weighted-type spaces, J. Ineq. Appl. 2015 (2015), 265, DOI 10.11866/s13660-015-0770-9.

[11] X. LiU AND S. LI, Differences of generalized weighted composition operators from the Bloch space into Bers-type spaces, Filomat, 31 (2017), 1671-1680.

[12] B. MACCLUER AND R. ZHAO, Essential norm of weighted composition operators between Bloch-type spaces, Rocky. Mountain J. Math. 33 (2003), 1437-1458.

[13] K. Madigan And A. Matheson, Compact composition operators on the Bloch space, Trans. Amer. Math. Soc. 347 (1995), 2679-2687.

[14] P. Nieminen, Compact differences of composition operators on Bloch and Lipschitz spaces, Comput. Method Funct. Theory 7 (2007), 325-344.

[15] J. Shapiro And C. Sundberg, Isolation amongst the composition operators, Pacific J. Math. 145 (1990), 117-152. 
[16] Y. SHI AND S. LI, Essential norm estimates for differences of composition operators on the Bloch space, Math. Ineq. Appl., 20 (2017), 543-555.

[17] S. STEVIĆ, Norm and essential norm of composition followed by differentiation from $\alpha$-Bloch spaces to $H_{\mu}^{\infty}$, Appl. Math. Comput. 207 (2009), 225-229.

[18] S. STEvIĆ, Products of composition and differentiation operators on the weighted Bergman space, Bull. Belg. Math. Soc. Simon Stevin 16 (2009), 623-635.

[19] S. STEVIĆ, Weighted differntiation composition operators from mixed-norm spaces to weighted-type spaces, Appl. Math. Comput. 211 (2009), 222-233.

[20] S. STEvić, Weighted differentiation composition operators from the mixed-norm space to the nth weigthed-type space on the unit disk, Abstr. Appl. Anal. 2010 (2010), Article ID 246287.

[21] S. STEvić, Weighted differentiation composition operators from $H^{\infty}$ and Bloch spaces to nth weighted-type spaces on the unit disk, Appl. Math. Comput. 216 (2010), 3634-3641.

[22] S. STEVIĆ, Characterizations of composition followed by differentiation between Bloch-type spaces, Appl. Math. Comput. 218 (2011), 4312-4316.

[23] M. TJani, Compact composition operators on some Möbius invariant Banach space, $\mathrm{PhD}$ dissertation, Michigan State University, 1996.

[24] W. YANG AND X. ZHU, Differences of generalized weighted composition operators between growth spaces, Ann. Polon. Math. 112 (2014), 67-83.

[25] Y. WU AND H. Wulan, Products of differentiation and composition operators on the Bloch space, Collet. Math. 63 (2012), 93-107.

[26] H. Wulan, D. Zheng And K. Zhu, Compact composition operators on BMOA and the Bloch space, Proc. Amer. Math. Soc. 137 (2009), 3861-3868.

[27] R. ZhaO, Essential norms of composition operators between Bloch type spaces, Proc. Amer. Math. Soc. 138 (2010), 2537-2546.

[28] K. ZHU, Operator Theory in Function Spaces, American Mathematical Society, Providence, RI, 2007.

[29] X. ZHU, Products of differentiation, composition and multiplication from Bergman type spaces to Bers type space, Integ. Tran. Spec. Funct. 18 (2007), 223-231.

[30] X. ZHU, Generalized weighted composition operators on weighted Bergman spaces, Numer. Funct. Anal. Opt. 30 (2009), 881-893.

[31] X. ZHU, Generalized weighted composition operators from Bloch spaces into Bers-type spaces, Filomat 26 (2012), 1163-1169. 